ISCKMC 2020

International Scientific Congress «KNOWLEDGE, MAN AND CIVILIZATION»

\title{
EVALUATING THE FINANCIAL CONDITION OF AN ENTERPRISE USING UNIVERSAL PROCESS MODELING
}

\author{
Anastasiya Aleksandrovna Rukosueva (a)*, Olga Vladimirovna Baryshnikova (a), \\ Vadim Sergeevich Tynchenko (a, b, c), Svetlana Igorevna Lytkina (b), \\ Ekaterina Vladimirovna Rudyaga (a), Anna Aleksandrovna Leonteva (b)
}

(a) Reshetnev Siberian State University of Science and Technology, 31, Krasnoyarsky Rabochy Av., Krasnoyarsk, 660037, Russian Federation, vadimond@mail.ru

(b) Siberian Federal University, 79, Svobodny pr., Krasnoyarsk, 660041, Russian Federation, vadimond@mail.ru

(c) Marine Hydrophysical Institute, Russian Academy of Sciences», 2, Kapitanskaya St., Sevastopol, 299011,

Russian Federation, vadimond@mail.ru

\begin{abstract}
This article is devoted to the topic of automating the process of evaluating the financial condition of an enterprise. The work considers the essence and necessity of conducting financial analysis of the enterprise as a whole for all organizations, and the tax service in particular. The article presents methodology for financial analysis of an enterprise. The study demonstrates the advantages of a comprehensive assessment of the financial condition of an enterprise, examines the features of rating assessment of the financial condition of an enterprise and describes in detail the system of indicators that gives the most exact data. The work reveals the value for financial analysis of such parameters as profitability, liquidity, autonomy coefficient, financial stability coefficient and equity coefficient, and provides ways to improve them. The article analyzes and selects software that allows one to automate business processes without unnecessary costs for the customer. The algorithm of the program for assessing the financial condition of organizations is given and the result of its work is described in detail. This article shows the results of testing the program on data from an existing organization.
\end{abstract}

2357-1330 @ 2021 Published by European Publisher.

Keywords: Financial condition, enterprise, process, modelling, methodology 


\section{Introduction}

In accordance with Article 2 of the Federal Law No. 127 "On Insolvency (Bankruptcy)", insolvency (bankruptcy) is understood as the inability of the debtor to fully satisfy the creditors' claims recognized by the arbitration court monetary obligations, payment of severance pay and (or) remuneration of persons who work or worked under an employment contract, to fulfill the obligation to pay mandatory payments (Federal Law).

The risk of insolvency (bankruptcy) is that the company may completely stop its production and sales activities and be liquidated as a legal entity. The risk of bankruptcy is inherent in absolutely any commercial organization, no company is insured against this type of risk.

«Fedresurs» calculated that the number of decisions on declaring companies bankrupt has decreased (-26\%) when comparing the first six months of 2020 and 2019, based on reports from arbitration managers in the Unified Federal Register of Bankruptcy Information. The indicator decreased from 6083 units to 4502. In the second quarter of this year, there was a significant decrease in the indicator by $39.8 \%$ (to 1895 ), in the first - by $11.2 \%$ (to 2607 ). In June, the growth accelerated, and the courts adopted $30.5 \%$ more rulings on the recognition of bankruptcy of companies ( +963 pieces) (Fedresurs).

\section{Problem Statement}

This article is devoted to the topic of automating the process of evaluating the financial condition of an enterprise. The algorithm of the program for assessing the financial condition of organizations is given and the result of its work is described in detail. This article shows the results of testing the program on data from an existing organization.

\section{Research Questions}

The work considers the essence and necessity of conducting financial analysis of the enterprise as a whole for all organizations, and the tax service in particular. The article presents methodology for financial analysis of an enterprise. The study demonstrates the advantages of a comprehensive assessment of the financial condition of an enterprise, examines the features of rating assessment of the financial condition of an enterprise and describes in detail the system of indicators that gives the most exact data. The work reveals the value for financial analysis of such parameters as profitability, liquidity, autonomy coefficient, financial stability coefficient and equity coefficient, and provides ways to improve them. The article analyzes and selects software that allows you to automate business processes without unnecessary costs for the customer.

\section{Purpose of the Study}

The aim of this article is to create a model for assessing the financial condition of an enterprise that can be used by both legal entities of any size and employees of the Federal tax service of Russia.

And the model must be created with the following conditions in mind: 
- The model should be developed in the program established by most business managers, as well as in the Federal tax service of Russia.

- The model must be accessible without special knowledge.

- The model should be applicable to any enterprise of any size and any industry.

- The model should provide concrete options for improving the company's condition.

\section{Research Methods}

The most appropriate method of financial analysis (Kashirina, 2016) for our purposes is a comprehensive assessment of the financial condition of the enterprise. A comprehensive assessment involves determining its economic potential, which makes it possible to identify its place in the economic environment. Also, a comprehensive analysis makes it possible to identify problematic aspects of the company's activities and find out the reasons that caused them, but it is very difficult to draw detailed conclusions about the financial condition of the company as a whole. In our article, we presented the results of our analysis in the form of a rating.

Rating assessment of the financial condition of an enterprise is a tool for on-farm, but to a greater extent inter-farm comparative analysis, assessment of its investment attractiveness. A rating is a generalized quantitative characteristic of an enterprise that determines its place in the market. Rating determination can be based on a system of absolute and relative indicators, or on a combination of both. We have selected ten indicators that assess the financial condition of the enterprise from different sides, namely: return on sales by net profit, return on assets, financial autonomy, current liquidity, sales growth (without VAT), return on sales by profit from sales, increase in equity capital, rapid liquidity, the coefficient of providing current assets with own funds, the coefficient of financial stability. These indicators most fully show the state of the enterprise, while they are not functionally dependent, do not duplicate or contradict each other (Chistyakova, 2019). The algorithm of the final rating assessment was built on the basis of the expert-point method, in which each reliability class is assigned a certain number of points and a regulatory base is formed for the rating number, i.e. rating groups, each of which corresponds to a certain range of points and the rating is determined by adding points (Analysis of the financial condition of the company).

The profitability of products sold by net profit allows you to determine approximately how much profitability will increase if the sales level increases by 1 ruble. The value of the indicator indicates how much net profit the company received for each ruble of services or goods sold. A negative value indicates the need to search for reserves to reduce the level of expenditures, that is, it is necessary to optimize the structure of financial resources and reduce the cost of attracting them, use tax incentives, reduce the cost of production of goods and services, and optimize the cost of marketing communications. A high value of this indicator may indicate a high value of the product or service to the consumer, a strong competitive position, and a high level of management professionalism (Finstanon).

Return on assets displays the ratio of net profit to the value of a particular type of property in an organization. This indicator is considered as one of the main indicators of the quality of investment made by the firm. This indicator, which does not consider the impact of borrowed funds, characterizes the effectiveness of the organization, the quality of management and reflects the company's competitive 
position in the market, expansion opportunities, and the quality of enterprise management. That is, if, for example, the return on assets of an enterprise is $15 \%$, it means that each ruble of assets that was used in the enterprise's activities brought it 0.15 rubles. If the value of the indicator exceeds the cost of long-term borrowed funds, this indicates low profitability. A negative value indicates the degradation of the enterprise. Optimizing the structure of assets will reduce their volume and increase profitability, provided that the volume of generated profit increases or remains at the previous level. In other words, it is necessary to work towards reducing the amount of expenses and increasing revenues.

The financial autonomy coefficient is calculated as the ratio of equity and reserves to the total assets of an enterprise and shows how independent the organization is from creditors. The lower the coefficient value, the more dependent the organization is on borrowed sources of financing, and the less stable its financial position. For example, if a company is able to generate profit and is solvent in the current conditions, this does not mean that the company will be able to act consistently when the market situation changes. A low share of equity is usually accompanied by significant financial expenses (interest payments, other expenses for raising and using borrowed funds). If the value of the financial autonomy indicator is too high, and there is potential for the company to grow, increase market share, increase sales, and improve performance by attracting additional funds, it is advisable to attract additional borrowed funds.

Current liquidity reflects the company's ability to repay current (short-term) liabilities using only current assets. The higher the indicator, the better the company's solvency. Current liquidity is a key indicator of the financial condition of any enterprise, and it must be constantly monitored. The growth of the coefficient makes the company more attractive to investors and creditors, which gives it more additional leverage and monetary resources while increasing the market value, including profitability. The high value of indicators is negative, because it indicates an excessive diversion of the company's resources to the formation of funds, which leads to inefficient use of available financial resources. The low value of liquidity indicators is negative, because it indicates problems with the ability to meet their short-term obligations. This reduces the confidence of contractors and partners in the company, which negatively affects the cost of attracting borrowed resources - Bank and commercial loans, and leads to an increased risk of solving financial problems in court. To increase the value of current liquidity, it is necessary to work towards increasing the amount of current assets and reducing the amount of current liabilities. To reduce the amount of current liabilities, for example, you can agree to provide credit funds for a longer period of time.

Sales growth (excluding VAT) is an economic indicator that reflects the change in the amount of income of an enterprise over a certain period of time. In other words, this indicator allows you to see how much percent the company's revenue increased (decreased) in the reporting period compared to the previous one. This indicator should be constantly under the control of the organization's management, since its value allows us to draw conclusions about the effectiveness of implementing the company's strategic and operational goals. The increasing revenue of the company indicates an increase in sales volumes, which in turn depend on the following factors: the quality of products; reasonable pricing policy; established sales channels; effective advertising events, etc. In order to increase revenue, you can 
reduce the cost of production, create and implement a program to motivate the team, adjust the advertising policy and increase the volume of products produced (Kuzmina \& Mundusova, 2018).

Return on sales measures the amount of operating profit (gross profit less other operating expenses) generated by each ruble of sales. In other words, the higher the operating profit margin, the better the company performs its activities. Typically, businesses that show a tendency to increase operating profit margins also show an increase in overall cost management efficiency. If the value of the indicator is lower than the standard or desired, it is advisable to look for ways to reduce operating expenses, namely sales expenses, management expenses, expenses for ensuring the production process, and other operating expenses. For example, such activities can be the use of software that will free up some of the labor resources, optimize the cost of maintaining the office, optimize the cost of marketing communications, etc.

The increase in equity allows you to estimate the rate of capital growth and understand what kind of dividends it will bring to investors in a certain period. The main form of increasing the company's equity capital should be the distribution of net profit to reserve funds formed in accordance with the constituent documents, and funds for accumulating or preserving retained earnings for the purposes of the main activity with a significant restriction on its use for non-production purposes. In case of an unfavorable ratio of net assets (real equity) and authorized capital, the increase in the latter will lead to an equal increase in these indicators and will not change their ratio for the better. Therefore, from the point of view of financial stability, an increase in real equity at the expense of authorized capital makes sense only if there is a sufficient level of real equity. From the above, it follows that an enterprise that has allowed its own capital to decrease to negative values will worsen its position every day if urgent measures are not taken to optimize profitability. To develop a strategy for improving the financial condition, it is necessary to identify effective optimization levers by conducting a structural analysis of costs and profitability. If the amount of losses has reached extremely high values, we will have to take drastic measures, including reducing production funds. Thus, the change in equity as a result of the company's ordinary activities is determined primarily by the net profit (loss) received in the reporting period. If there is no (or insignificant) influence of other factors, the main way to increase equity is to deduct the reserve capital from net profit and accumulate retained earnings as a source of financing for ordinary activities with a significant restriction on the use of profits for other purposes (Negashev, 2013).

Rapid liquidity is an indicator of a company's short-term liquidity that measures a company's ability to pay off its short-term liabilities on time with highly liquid assets. Highly liquid assets include cash and cash equivalents, current financial investments, accounts receivable, etc. This indicator is similar to the current liquidity indicator, as it shows the company's solvency level. However, the rapid liquidity indicator is stricter and more accurate, because it allows you to exclude less liquid current assets. In order to form accurate conclusions, it is necessary to compare the indicator with previous years and other companies in the industry. A business that sells goods and services for cash without using commercial loans will remain solvent at a relatively low level of rapid liquidity. Conversely, if a company actively lends its customers with commodity loans and the turnover of accounts receivable is low, then a higher value of the rapid liquidity indicator is desirable. If the value of the indicator is lower than the standard, then you should work towards increasing the amount of highly liquid assets and reducing the amount of 
current assets. To increase the value of the rapid liquidity indicator, enterprises should pay attention to ways to accelerate the turnover of their own funds invested in inventory. In particular, you can actively use such a financial instrument as issuing shares, providing short-term loans to other organizations, you can also encourage buyers to pay on time with a discount system, or by providing a commercial loan, and for late payment, you can impose penalties and penalties for violating the terms of the agreement.

The indicators of provision of own working capital reserves is an indicator of the sufficiency of long-term funds of the company to ensure a smooth production and sales process. The indicator is calculated as the ratio of own working capital to the amount of inventory. The value of the indicator indicates the share of reserves that is financed by resources raised on a permanent basis. The indicator should be considered in dynamics. The increase in this indicator demonstrates an increase in the company's stability in the medium term and a decrease in its dependence on short-term sources of financing. The negative value of the indicator suggests that without short-term debt capital, the company will not be able to ensure a smooth production and sales process. In the context of reduced opportunities to attract such funds, the operational process may stop. To increase the value of the indicator, it is necessary to work towards increasing the amount of equity and reducing the amount of short-term borrowed funds. Optimization of the structure of current and non-current assets will free up some of the financial resources, which will have a positive impact on the value of the indicator. In General, the measure to increase the value of the indicator should consider the current situation and the company's capabilities.

The financial stability ratio is calculated as the ratio of the amount of equity and long-term liabilities to the amount of liabilities. The value of the coefficient indicates how much of the company's assets can be financed with fixed capital and capital raised on a long-term basis. The high value of the indicator suggests good prospects for the company's development and a low risk of bankruptcy. A low value indicates that there is some risk of loss of solvency (provided that access to short-term liabilities is limited). To increase the indicator, you can increase the amount of equity or increase the amount of longterm borrowed funds. Activities in the first direction can be: reinvestment of profits, additional issue of shares, etc. Activities in the second direction can be: issuing bonds (for a period of more than a year), receiving a loan from a Bank, receiving credit funds from other enterprises, etc. (eFinanceManagement.com).

Thanks to these indicators, we conducted a comprehensive assessment of the company's financial condition.

Each indicator is assigned a score of -1 to 1 , but for each, depending on its norm, moreover, the entrepreneur will be given advice on improving the state of the enterprise. As a result, we will get the total coefficient of the company's state within the calculated range shown in table 01 . 
Table 1. The total coefficient of the company's condition within the calculated range

\begin{tabular}{|c|c|c|c|}
\hline \multicolumn{3}{|c|}{ Point } & \multirow{2}{*}{ Condition } \\
\hline & From (inclusive) & Before & \\
\hline 1 & 0.8 & & Excellent \\
\hline 0.8 & 0.6 & & Verygood \\
\hline 0.6 & 0.4 & & Good \\
\hline 0.4 & 0.2 & & Positive \\
\hline 0.2 & 0 & & Normal \\
\hline 0 & -0.2 & & Satisfactory \\
\hline-0.2 & -0.4 & & Unsatisfactory \\
\hline-0.4 & -0.6 & & Bad \\
\hline-0.6 & -0.8 & & Critical \\
\hline-0.8 & -1 & & Potentialbankruptcy \\
\hline
\end{tabular}

\section{Findings}

We created our model based on the Microsoft Office Excel package, since it is most often installed on the computers of entrepreneurs and is included in the approved list of programs for budget institutions.

Automating the assessment of the financial condition of enterprises using Microsoft Excel will lead to increased productivity of employees and managers, easier access to information for making managerial decisions, improved performance discipline, and therefore, to an overall improvement in the quality of management.

Input information for the program is the balance sheet - the most important form of accounting (form \#1), which can be used to judge the financial condition of the enterprise, what property it has and how much debt it has. The balance sheet contains data as of a certain date (usually the end of the year or quarter) in this case for the last two years (Klaas \& Vagizova, 2014).

For the convenience of using the program we have created an interface in Visual Basic (figure 01).

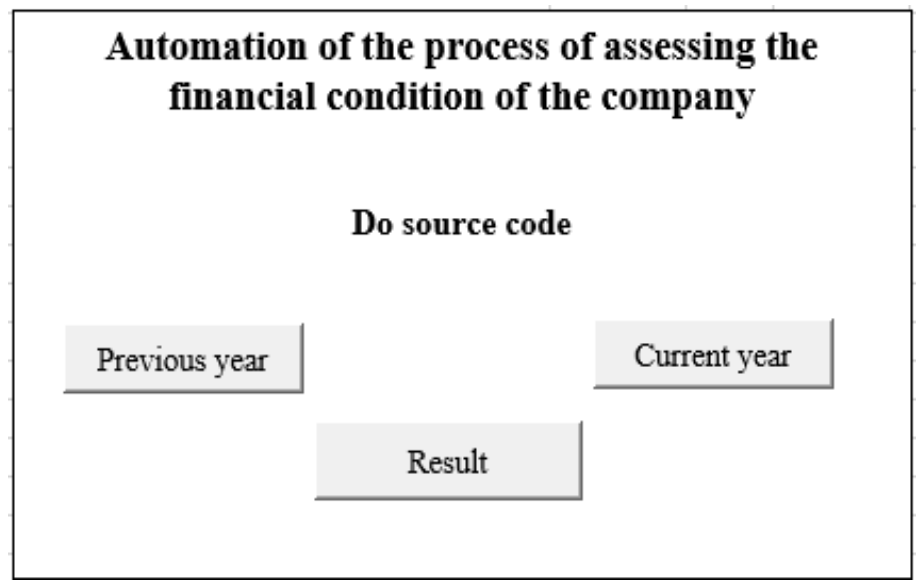

Figure 1. Interface 
Output information is a conclusion about the state of the enterprise and the schedule of development of the enterprise for the selected period, formed by this system.

As a result, we received a result in tabular form with detailed information for each indicator, as well as a conclusion about the financial condition of the company in graphical form for clarity of results (figure 02).

A note has been added to each indicator, and a tip on how to improve it has been added to the final value (figures 03 and 04).

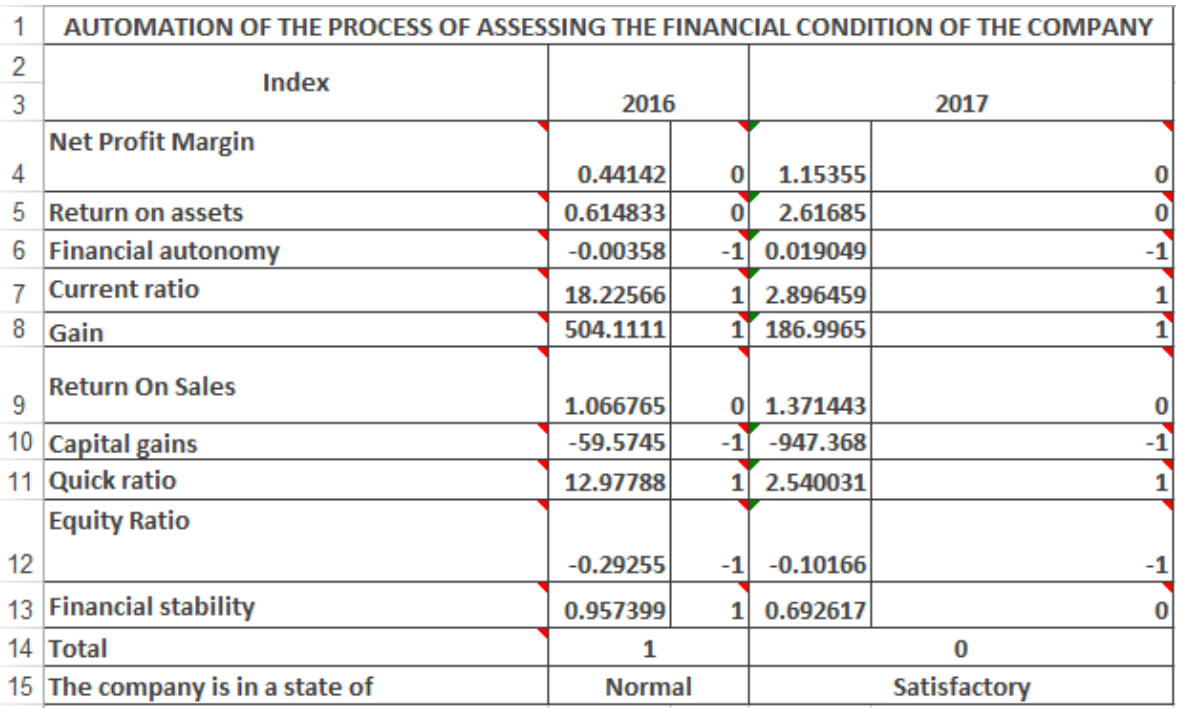

Figure 2. Output information

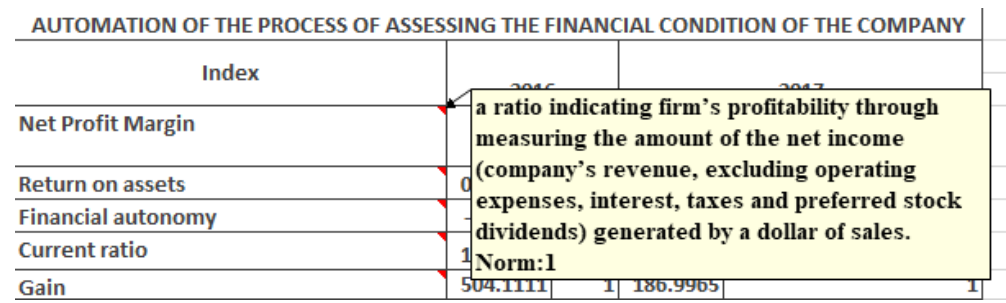

Figure 3. Note

\begin{tabular}{|c|c|c|c|}
\hline Index & & & \\
\hline Net Profit Margin & 0.44142 & 0 & $\begin{array}{l}\text { *Optimization of the finance structure } \\
\text { and declining the cost of the funds }\end{array}$ \\
\hline Return on assets & 0.614833 & 0 & invorvement; \\
\hline Financial autonomy & -0.00358 & -1 & *Declining the cost of production for \\
\hline Current ratio & 18.22566 & 1 & goods and services; \\
\hline Gain & 504.1111 & 1. & *Optimization of the marketing \\
\hline Return On Sales & 1.066765 & $\mathbf{0}$ & \begin{tabular}{l}
\multicolumn{1}{|c}{ communications expenses. } \\
.371443 \\
$0 \mid$
\end{tabular} \\
\hline
\end{tabular}

Figure 4. The Council 
As a result of this work, a model was created that helps to make a conclusion about the current state of the organization and its development schedule for the selected period, which clearly shows the state of the enterprise and its development prospects (Figure 05).

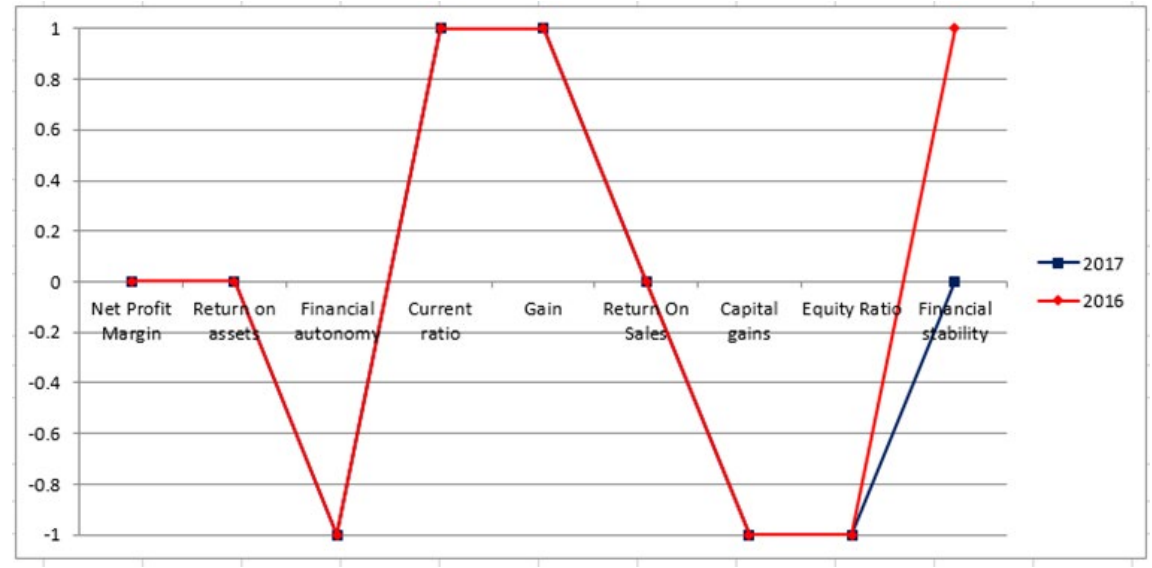

Figure 5. The schedule of the organization's development

\section{Conclusion}

As a result of this work, a model was created that helps to make a conclusion about the current state of the organization and its development schedule for the selected period, which clearly shows the state of the enterprise and its development prospects, as well as gives advice on improving the state of the enterprise.

At the moment, the information subsystem is being tested by the small enterprise and the Interdistrict IFTS No. 24. The model for assessing the financial condition of the company has significantly facilitated the work of employees of the Federal tax service and increased the efficiency of their work, as well as helped the head of the company to identify the shortcomings of their business and correct them.

We plan to test the model at larger enterprises.

\section{References}

Bezzubov, M. Y. (2017). Analysis of the financial condition of the organization "TEKHNOSREDA" LLC. http://e-koncept.ru/2017/770355.html

Chistyakova, A. P. (2019). The value of factor analysis in assessing the financial position of a commercial enterprise.Young scientist, 6(244), 156-158.

Kashirina, E. A. (2016). Review of methods of financial analysis of Efimov. https://cyberleninka.ru/article/n/obzor-metodov-finansovogo-analiza.html

Klaas, J., \& Vagizova, V. (2014). Tools for assessing and forecasting financial stability of the commercial bank under conditions of instability.Investment Management and Financial Innovations, 4(11), 157-163.

Kuzmina, E. E., \& Mundusova, S. M. (2018). The Impact of the financial cycle on the company's sustainable growth. Economics and business: theory and practice, 6, 99-102.

Negashev, E. I. (2013). Analysis of the required increase in the company's equity. Audit and financial analysis, 5, 138-146. 